\title{
CONCRETE POLES OF TRANSMISSION LINES ON THE END OF SERVICE LIFE
}

\author{
Nada Curović* \\ Public Enterprise Elektromreza Srbije, Belgrade, Serbia
}

Transmission system in Serbia, due to its age, inevitably enters the period of active investment project of reconstruction, adaptation and rehabilitation of the transmission lines. Today we are faced with the fact that the transmission lines are constructed more than 60 years ago, and are still in service. The paper discusses the problems in the implementation of projects of rehabilitation of reinforced concrete transmission line route. The results of experimental research, load test of reinforced concrete poles are show. It explains the problems in the management of investment projects of rehabilitation in these lines. On the bases of analyzed opportunities and best practices all possible alternative sceneries are given for reinforced concrete poles of transmission lines in the network. Multidisciplinary comparison is made for these alternatives and presented the advantages and disadvantages of each variant. The analysis pointed to solution - application of steel lattice towers instead of reinforced concrete. Project management of rehabilitation and reconstruction of the transmission line in the coming period will be a great deal with which will meet the engineers. However, an even greater engineering challenge will be deciding on the proper manner and dynamics of realization of projects for each line.

Key words: Reinforced concrete poles, Loading test, Repairing, Multi criteria Optimization

\section{CONDITION OF REINFORCED CONCRETE POLES IN TRANSMISSION LINE GRID}

When we talk about this kind of transmission towers, we should be awere about ages of constructions. Their are constructed about half of the last century. Mass production of structural steel, introduced steel as the main material in the industry of the high-voltage transmission lines. Steel structures have allowed significantly fast$\mathrm{er}$, and therefore cheaper constructings. On the other hand, steel is brought the ideal ratio (characteristics+ flexibility) / price. This inevitably led to the extrusion of concrete poles from the high voltage network in sixties, although some of the good qualities of concrete poles, like a small dimensions in bases of poles, steel lattice towers could not keep.

Considering the development of events in the past, the consequences are reflected on the situation in the system today. Some of the more important issues are the following:

- The poles are old and outdated materials requires urgent rehabilitation

- For 60 years and over a large part of the technical documentation is unfortunately lost

- During the past years there was no construc- tion of concrete poles, so Project documentation, never harmonized with changes in technical regulations. In this way, even projects we have today are not usable.

- Technical requirements lines have today, can not be met with the parameters of the poles built more than a half century ago

- It is a large number of lines with concrete poles, since the fifties and sixties of the last century was a period of expansive development of the transmission system in the country.

Since the large number of these lines can not be all reconstruct parallel and change. High voltage network in Serbia is not highly developed system. So it is impossible to exclude a large number of lines from the system (to pulled down poles and replaced by new ones), without significant problems in electrical supply. Also these are financially extremely large investment projects. The project of replacing concrete poles with lattice steel towers, in financial terms is as well as construction of new transmission lines, which is further loaded by the cost of removing the existing poles. 


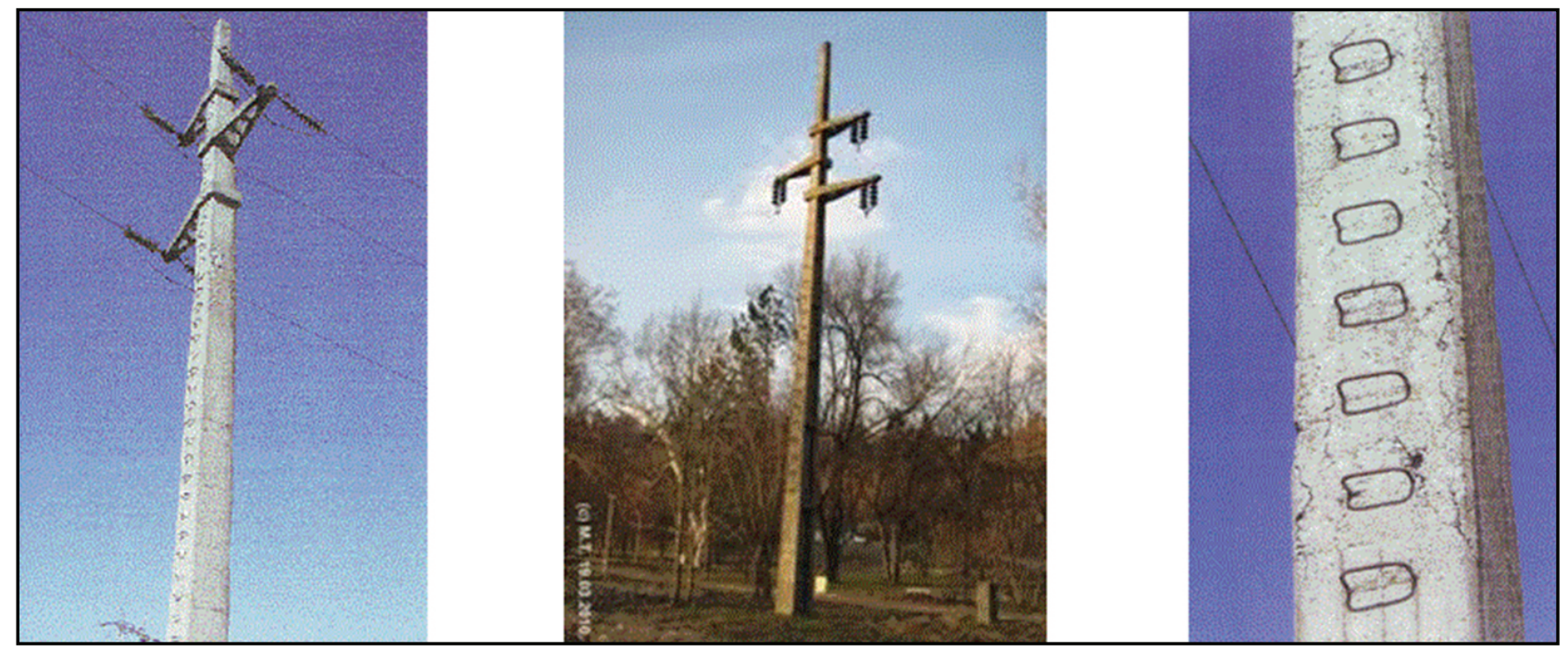

Figure 1: Condition of poles

\section{LOAD TEST OF CONCRETE POLES}

As it is impossible to make a complete reconstruction of the whole grid at once, it was necessary to examine the constructive potential of existing poles, in order to determine the possibilities for their use. It was necessary to check whether it is possible to apply forces of the new equipment to the old poles. This would prolong lifetime of poles, and increase lines capacitance, adequately to the demands of demographic development in the region. In order to determine the actual capacity of the poles at the end of their life cycle, as well as to confirm the safety and security of the system, load tests were carried out on concrete poles. Testing was conducted in accordance with European standards and was on the model, but on the already existing structure. Pole that is not in operation and which is on the route of an abandoned part of line OHL 110 kV Niš - Leskovac, near Leskovac, was used for load tests. Pole cross-section is square with a linearly varying cross-sectional dimensions in accordance with increasing height. Pole height is $25.35 \mathrm{~m}$. Cross-section on earth level is dimension $80 \times 80 \mathrm{~cm}$. Pole is built by conventional method of casting on the spot. It is important to note that the pre-examination established that the poles of the abandoned line is completely appropriate to poles on the active power line. In order to demonstrate that, the concrete is stripped off on a one pillar in the active line, and it is determined the number and position of reinforcement bars in cross-section of the poles. The scope of works covered by the examination was as follows:

- Determining the quality of concrete and the 362 concrete steel. Sampling pole is one that not tested in the load test, as weakened sections does not affect the resultats. Samples were taken from three spots of the column.

- Determination of stresses in concrete and reinforcement for a given load case

- Deformation measurement in specific points

- Measurement of displacement and deflection of foundation

- Demolition of the entire pole with the foundation and removing the material after the review

The relevant load case, in accordance with the technical documentation for the rehabilitation of the transmission line, is the case load 68.1 / b according to the „Rules on technical norms for construction of overhead electrical power lines with a nominal voltage from 1 to $400 \mathrm{kV}$ ". Schematic representation of the applicable load case is done for the following technical parameters of the line:

Conductor: Al/Č 150/25 mm²

Maximum working stress: $9.75 \mathrm{daN} / \mathrm{mm}^{2}$ Wind pressure: $60 \mathrm{daN} / \mathrm{m}^{2}$

According Internation IEC (International Electrotechnical Commission) standard 60652 - Loading tests on overhead line structures, plan for phase load of pole is made (5-phase load test). $50 \%$, $75 \%, 90 \%, 95 \%, 100 \%$ of design's loads. The amount of the applied load was measured with a dynamometer 6 . Sizes of horizontal and vertical displacement were measure by calibrated measuring instruments. Local deformation sizes (dilatation-stress) were measured using strain types and accuracy of $10^{*} 10 \mathrm{E}^{-6}$. Schematic position of the load cycles apply is shown in Figure 2. 


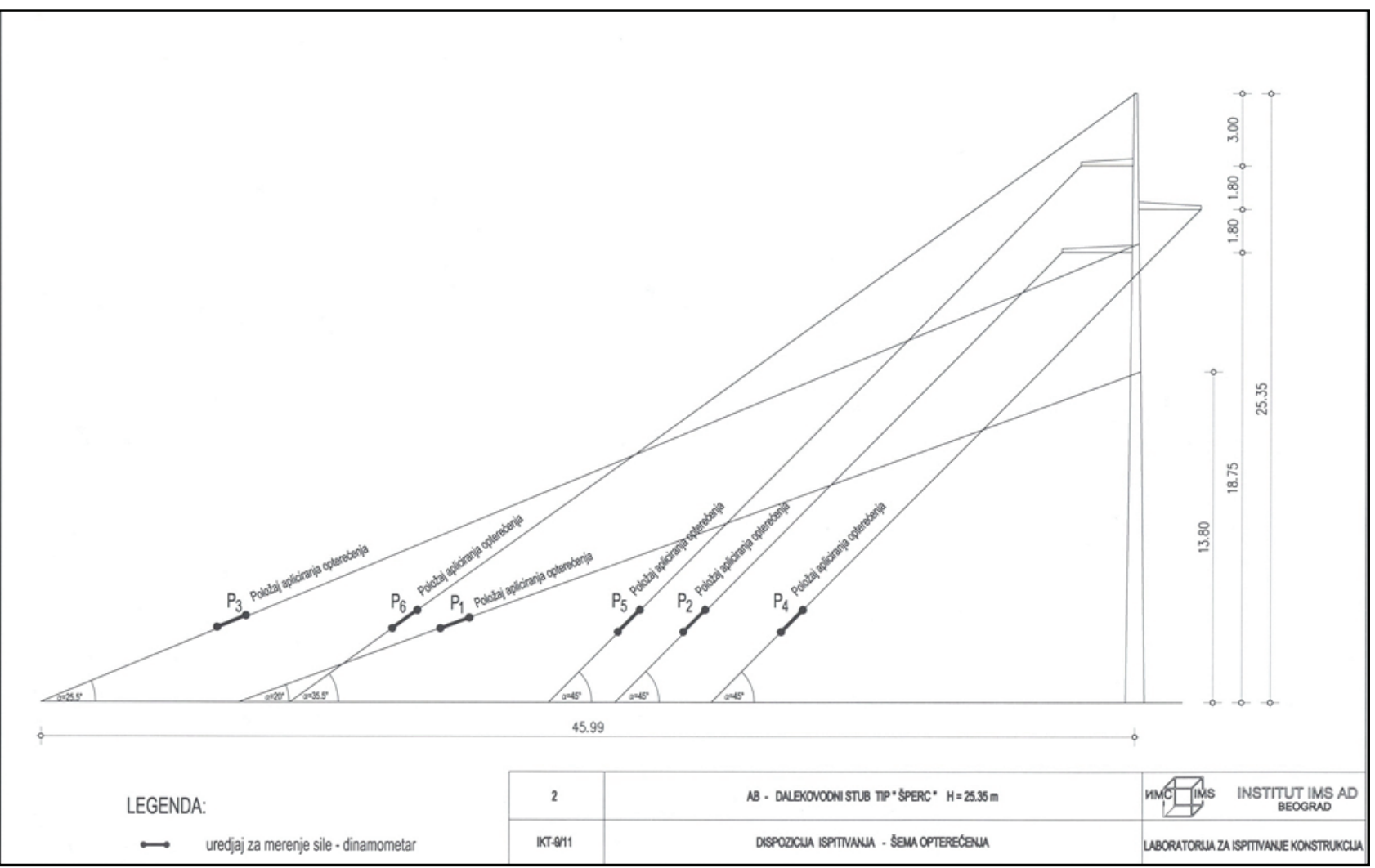

Figure 2: Schematic position of the load cycles apply

In the context of pre-defined criteria for assessing the quality of the test poles, definitions of fracture is determined. Fracture occurs when the local deformations increase or increase the horizontal scrolling without increment of static loads Fracture occurs when the total length of cracks in $200 \mathrm{~mm}$ greater than $1.5 \mathrm{~mm}$. Old equipment and conductors apply the force with $70 \%$ of the

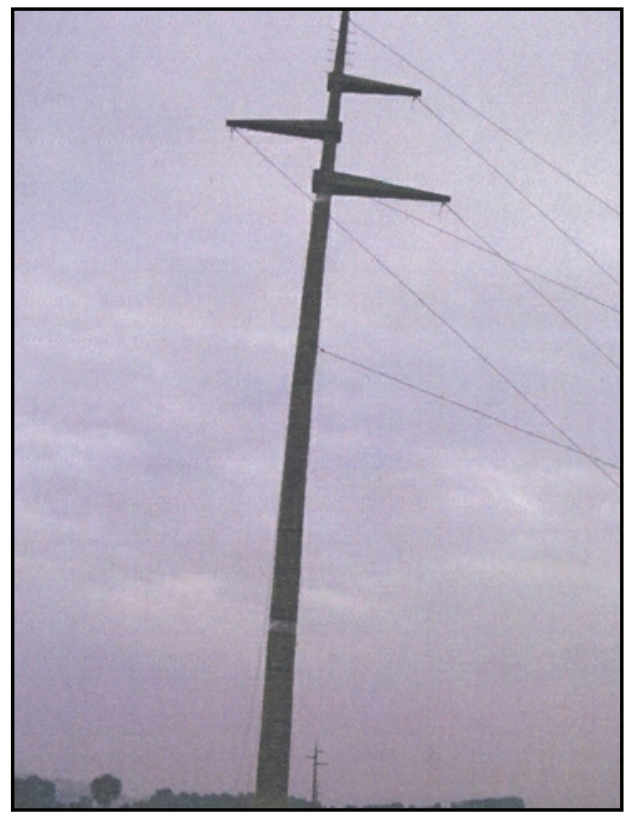

Figure 3: Deformed position, the breakages in the third phase loads load in relation to the newly designed. After the second phase ( $75 \%$ of the workload), there is the appearance of cracks in the concrete around the measuring cross-section 1-1 of the base of the column. Between II (75\%) and stage III (90\%) there was an increment of deformation without increasing the load level. Specifically, there was a fracture of the poles.

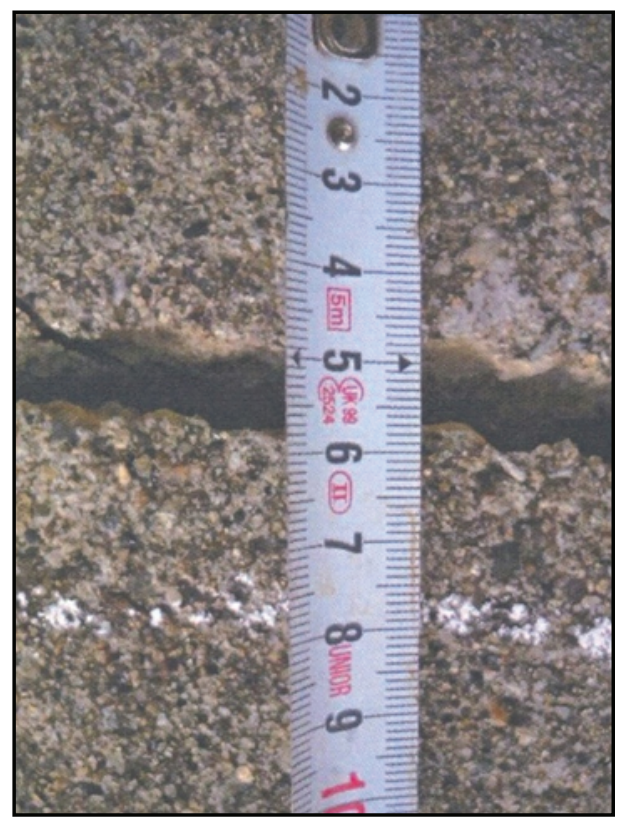


This is exactly experimentally proven that the reinforced concrete poles on the route of the transmission line, can not carry the required loads of new designed equipment and conductors. It was also proved that it can safely and reliably carry the existing equipment. More specifically, each replacement of equipment and upgrading of power line must involve work on the poles, repair / replacement of structural elements, transmission line towers. It is interesting to say that samples of material of concrete and steel bars, after more then 60 years (the line is built 1954.) satisfy the mechanical characteristics of the prescribed standards.

\section{ANALYSIS OF POSSIBLE PROBLEM SOLUTIONS}

Capacity problem of concrete pillars in the 110 $\mathrm{kV}$ network is a system problem. Legislation on non-ionizing radiation brings added height requirements that often these poles can not fulfill. Definitely withdrawal of reinforce concrete poles can not be accepted, without analyzed and advantages of this type of towers. The primary advantage is small dimensions in the base of the column, which is usually less than $1 \mathrm{~m} 2$ at zero level above the ground. Also important advantage relates to the nature of the material. Reinforced concrete does not require any periodic maintenance, as opposed to steel with an anticorrosion protection is extremely important to maintain the designed technical characteristics. In conditions in which the high-voltage grid operates in Serbia, there is the advantage that there is no possibility of theft of structure, which is an extraordinary problem in the case of steel lattice towers.

The analysis of all available technical solutions singled out the following solutions:

\section{Rehabilitation of reinforced concrete poles}

The advantage of this variant, in which the poles retain, is the speed of realization of the activities. There is also no need for additional footprint for pole positions and settlement of property relations that always carries a certain risk for the project. The disadvantage is that even after repair we use basically outdated material. From the standpoint of sustainability solutions, this is the most short term solution. Exploitation period is extended, but not in the same period as the construction of new towers. Remediation methods available today are not applied to the columns of power lines and there is no experience that would demonstrate the behavior of the material after rehabilitation. The three options of poles rehabilitation available on the domestic market are:

a) coating laminated steel plates on the pole surface glued by epoxy

b) the refurbishment by carbon fiber

c) coating the existing pole by concrete ring

\section{2) Construction of new reinforced concrete poles}

Construction of new reinforced concrete columns would be a variant, which requires a longer period of time for implementation. The above mentioned advantages of concrete poles would remain, however, we are faced with several disadvantages. There is no valid technical documentation for these columns, and it would be necessary to design new. If the poles cast onsite construction process would be slowed down considerably. The process of concrete curing and reaching the designed strength exceeds the speed of erection of lattice steel towers dozens of times. In this case it would be necessary to provide alternative power supply due to the exclusion of power line for significantly longer periods. If you would allow use of prefabricated structure, it would be necessary to engage the heavy machinery that can handle heavy concrete elements. Specific gravity of concrete $2500 \mathrm{~kg} /$ m3 determined higher capacity cranes needed, and therefore affects the increase in construction prices. Also, there remains a certain limit of available height.

\section{3) Replacing poles with lattice steel towers}

Steel lattice towers are typically towers in transmission systems in the world today. Their flexibility, the possibility of typing elements, speed of construction, assembling/disassembling structure, and also price made them common types of towers from which could withdraw only in case of specific conditions of the terrain and when there are special requirements, such as the construction in or near settlements and urban areas. Occupancy in the base is increased, however, advantages in other categories compensating for this deficiency. The big advantage is that they are significantly lighter than concrete towers. An example of this is the ratio of the weight of the test concrete column and lattice steel tower of same height. Estimated weigh of concrete pole 
is about 21t, while lattice steel tower of same height (Design no.1-0.DV.G.1055) weight $2.65 \mathrm{t}$.

\section{4) Lattice Steel Towers with reduced base or steel pole}

This type will reconcile the advantages of concrete poles and steel towers. Occupancy in base is basically slightly higher than for concrete poles and advantages of steel towers are also present. The disadvantages are more complex construction of the foundations, specially in the case of a steel poles and significantly higher cost of construction lines. Each of these solutions carries specificity in terms of the dynamics of implementation, costs estimation, and sustainability of solutions. Table I provides an assessment of all variants with the specified criteria. For each criterion variants are ranked from 1 to 4 , by awarding points. Criteria already considered equal, without use of weighting coefficient. The introduction of weights coefficient could be seen from the point of preferential optimization criteria. Regard this, and also the condition of power grid today, more weight would be given to criteria 1,5 and 6 . It is primarily necessary to provide durable solutions which will be reliable and safe for a long period to ensure that the facility does not exclude from the system.

Criteria are as follows:

1. Sustainability of Solutions

2. Speed of implementation

3. Costs of implementation

4. Dimension of tower basis

5. Reliability, predictability in service and safety of solution

6. Flexibility / adaptability of solution

7. Visually aesthetic effect

Table 1: Evaluation of alternatives according to predefined criteria

\begin{tabular}{|l||c|c|c|c|c|c|c||c|}
\hline \multicolumn{1}{|c|}{} & \multicolumn{7}{|c|}{ CRITERIA } & \multirow{2}{*}{ TOTAL } \\
\cline { 2 - 9 } & $\mathbf{( 1 )}$ & $\mathbf{( 2 )}$ & $\mathbf{( 3 )}$ & $\mathbf{( 4 )}$ & $\mathbf{( 5 )}$ & $\mathbf{( 6 )}$ & $\mathbf{( 7 )}$ & \\
\hline Solution 1 & 1 & 4 & 4 & 4 & 1 & 1 & 1 & $\mathbf{1 6}$ \\
\hline Solution 2 & 2 & 1 & 1 & 4 & 2 & 2 & 2 & $\mathbf{1 4}$ \\
\hline Solution 3 & 4 & 3 & 3 & 2 & 4 & 4 & 3 & $\mathbf{2 3}$ \\
\hline Solution 4 & 3 & 2 & 2 & 3 & 3 & 3 & 4 & $\mathbf{2 0}$ \\
\hline
\end{tabular}

Scoring alternatives, as a result of multi-criteria optimization, provides replacement of reinforced concrete poles with steel lattice towers as best solution. As can be seen the preferred criteria 1 , 5 and 6 could provide a substantial advantage to variant which use of steel lattice towers.

\section{CONCLUSION}

Experiences with the performed tests and the development of projects of rehabilitation of lines were the basis for further decision-making on management of reinforced concrete poles in high voltage power grid.

Experimental studies in which structures greater than $20 \mathrm{~m}$ and weight of $20 \mathrm{t}$ are broken is in itself a major engineering challenge. The experiment was carried out outside the laboratory environment, and has successfully simulated the loads required parameters. The experiment is performed once and there is no place for error when you do not have a large number of samples and tests are expensive to repeatedly conduct. It was necessary to take into account the accuracy of the projected load, of high precision application of forces and the reading of stress and deformation during the test, but also the security of the participants in the test.

Although multi-criteria optimization studying indicated the selected variant application of steel lattice towers instead of reinforced concrete, in decision-making would be useful for each individual project carried out an analysis of the spatial parameters of the power line environment. In this sense, there are situations when the more expensive variants may be the right solution. A good example of this are the connecting lines within the city center, where visual aesthetic effect must have a significantly higher weighting than when the transmission line passes through uninhabited areas. 


\section{REFERENCES}

1) Bunić, S., (2011): Glavni projekat sanacije DV 110 kV br 113/1 Niš 1 -Niš 2., Beograd

2) Najdanović, D., (2009): Sanacije, rekonstrukcije i održavanje betonskih konstrukcija u visokogradnji , Građevinski fakultet, Beograd

3) Opricović, S., (1998): Višekriterijumska optimizacija sistema u gradjevinarstvu, Građevinski fakultet, Beograd

4) (1992): Pravilniku o tehničkim normativima za izgradnju nadzemnih elektroenergetskih vodova nazivnog napona od 1 do $400 \mathrm{kV}$
5) (2011): Izveštaj sa ispitivanja stuba br IKT 9/11, Institut za ispitivanje materijala Beograd

6) Internation IEC (International Electrotechnical Commission) standard 60652 - Loading tests on overhead line structures

7) (2014): Opšta tehnička dokumentacija, Stubovi visokonaponskih dalekovoda, JP Elektromreža Srbije, Beograd

Paper sent to revision: 19.05.2016.

Paper ready for publication: 29.08.2016. 